\title{
Stressful weight loss
}

\author{
Michal Ajzensztejn
}

Correspondence to Dr Michal Ajzensztejn; michal@doctors.org.uk

Accepted 5 May 2010 Published Online First 12 August 2010

\section{ABSTRACT}

This paper describes a patient initially diagnosed with autoimmune thyroiditis who undergoes a diagnostic and investigatory journey

Emily, a 15-year-old girl, with no previous medical history of note, presented to her general practitioner with symptoms of lethargy, dizziness and waking with nausea. Her general practitioner examined her and found her weight $60 \mathrm{~kg}(<75 \mathrm{th}$ centile), height $162 \mathrm{~cm}$ (25-50th centile) and body mass index (BMI) $22.9 \mathrm{~kg} / \mathrm{m}^{2}$. Her cardiovascular and respiratory examinations were both normal, though she was noted to have mild epigastric pain on abdominal examination. There was no pallor or goitre evident. She was commenced on a trial of domperidone for the nausea and epigastric pain. Blood tests were taken for full blood count, electrolytes, liver function test, glucose and thyroid function test (TFT). These came back showing deranged TFTs. Thyroid stimulating hormone (TSH) $14.05 \mathrm{mIU} / 1(0.3-5.6)$ and free thyroxine (fT4) $6.5 \mathrm{pmol} / 1$ (7.5-21.1). Thyroid peroxidase antibodies were positive. The remainder of the results were within normal limits for her age.

She was commenced on $100 \mu \mathrm{g}$ of levothyroxine, and her thyroid function soon became euthyroid on treatment.

Lethargy is a non-specific symptom, which often affects teenage children. It is most often nonpathological. However, if it is out of character and a cause for concern, several conditions should be considered. Adolescence is a stressful time, and the majority of teenagers will become more fatigued than in previous years partly due to increased life stresses and increasing demands placed on them from school, peers, family and sleep deprivation. ${ }^{1}$ A differential of pathological conditions should be borne in mind. Several pathologies can be insidious and present with very subtle signs, and so, it can be beneficial to carry out routine blood tests looking for anaemia, chronic renal failure, hypothyroidism and to consider infectious (eg, Epstein-Barr virus) or emotional causes for the change in behaviour. In addition to the baseline bloods tested, gastroenterological conditions such as inflammatory bowel disease and coeliac disease could be considered as Emily described symptoms of abdominal pain and nausea; these were not tested for on this occasion. In this instance, a diagnosis of autoimmune thyroiditis was made based on her deranged thyroid function and positive antithyroid antibody test.

\section{COMMENT}

Autoimmune thyroiditis (which, if associated with a goitre, is called Hashimoto disease) is a chronic inflammatory disorder of the thyroid gland with lymphocytic and cytokine-mediated thyroid destruction. Thyroglobulin autoantibodies/ thyroid peroxidise autoantibodies are present in $95 \%$ of cases of autoimmune thyroiditis. It affects female patients more than male patients, and this ratio difference increases with age. Autoimmune thyroiditis is more common in conditions associated with abnormal karyotype such as Turner's, Klinefelter's and Down's syndrome and as part of other autoimmune diseases. ${ }^{23}$ It usually results in hypothyroidism requiring replacement therapy with levothyroxine, although patients can remain euthyroid and need regular monitoring of their thyroid function.

Following her initial diagnosis, Emily started to develop panic attacks which were centred around eating. She had never eaten breakfast and became self-conscious about eating in school in front of her peers, so she began skipping lunch. This resulted in her eating only one meal a day. She began to lose weight. Over the following 4 months, she found school increasingly difficult and stressful. Four months after her initial presentation, she stopped attending school altogether because of anxiety and panic attacks. Her parents became increasingly concerned by her weight loss and her worsening anxiety. She was referred to a child and adolescent psychiatrist for review.

Eleven months after her initial presentation, Emily now weighed $40 \mathrm{~kg}$ ( 0.4 th centile) and her height $165 \mathrm{~cm}$ (50-75th centile), giving her a BMI of $14.6 \mathrm{~kg} / \mathrm{m}^{2}$. She was biochemically euthyroid throughout - TSH $0.7 \mathrm{mIU} / 1$ (0.4-4.0), fT4 22.9 pmol/1 (10.3-24.5). Emily was very needle phobic and would not eat at all for days before her blood test, so these were kept to a minimum.

A joint decision was reached with Emily's parents, paediatrician and psychiatric consultants that the most likely diagnosis was anorexia nervosa and that she would require admission to a specialist eating disorder centre.

Emily was admitted to a specialist eating disorder centre as an inpatient. She was diagnosed as having some body image distortion in keeping with a diagnosis of anorexia nervosa. However, it was also noted that she had some atypical features such as extreme anxiety with panic attacks on eating and absence of "fat phobia"; the food choices she made were not generally low in fat.

\section{COMMENT}

Anorexia nervosa is a psychiatric disorder characterised by a deliberate and extreme loss of weight, body image distortion and morbid fear of weight gain. ${ }^{4-7}$ Weight is obsessively controlled by means of deliberate starvation, excessive exercising, 
vomiting/purging and laxative, diuretic and diet pill abuse. Higher rates of childhood onset obsessive-compulsive disorder and social phobia are associated with anorexia nervosa. ${ }^{4}$ There is a female preponderance with only $10 \%$ of cases of anorexia seen in males. The incidence of anorexia nervosa is increasing, and it appears to be affecting children at younger ages, where there is a more equal sex ratio. The prevalence in the UK is thought to be approximately $1 \%$ in women aged $15-30$ years old. Mortality from anorexia is $20 \%$ and results from suicide and complications of starvation (table 1$).^{5}$

Management involves an individualised program usually in the outpatient but occasionally in the inpatient setting. The aim is to restore weight by approximately $0.5-1 \mathrm{~kg} /$ week. It generally combines nutritional rehabilitation, medical intervention, psychotherapeutic treatment, psychosocial rehabilitation and family therapies. Close monitoring during commencement of re-feeding is required as re-feeding syndrome can develop which can be fatal. This involves close monitoring of vital signs and blood tests to monitor electrolytes, phosphate, magnesium and glucose (table 2). ${ }^{4}$

Table 1 Signs and symptoms of anorexia nervosa 467

\begin{tabular}{ll}
\hline Physical examination & \\
Emaciation & Brittle nails \\
Lanugo hair & Constipation \\
Bradycardia & Dehydration \\
Hypotension & Enlargement of parotid gland \\
Cold peripheries & Dry skin \\
Decreased core body temperature & Loss of enamel on teeth \\
Blood test & \\
Hyponatraemia, hypokalaemia, hypochloraemia, hypocalcaemia, hypomagnaesia, \\
hypophosphataemia (predisposes to osteoporosis and cardiac abnormalities which \\
can result in life threatening arrhythmias) \\
Metabolic alkalosis \\
Anaemia \\
Endocrine \\
Amenorrhoea-oligomenorrhoea \\
Delayed puberty \\
Hypothyroidism \\
IGF-1 deficiency \\
Hypoglycaemia \\
Hypercholesterolaemia \\
\hline
\end{tabular}

Table 2 Diagnostic criteria for anorexia nervosa ICD $10^{18}$

A. Weight loss, or in children; lack of weight gain, leading to a body weight of at least $15 \%$ below the normal or expected weight for age and height

B. weight loss is self-induced by avoidance of fattening foods

C. A self-perception of being too fat, with an intrusive dread of fatness, which leads to a selfimposed low weight threshold

D. A widespread endocrine disorder involving the hypothalamic-pituitary-gonadal axis, manifest in the woman as amenorrhoea and in the man as a loss of sexual interest and potency (an apparent exception is the persistence of vaginal bleeds in anorexic women who are on replacement hormonal therapy, most commonly taken as the contraceptive pill)

E. Does not meet criteria $A+B$ of bulimia nervosa

Emily's initial examination found her to be hypotensive, BP 80/60 mm Hg, tachycardic, HR $105 \mathrm{bpm}$ with cool peripheries and an axillary temperature, $35.4^{\circ} \mathrm{C}$.

Bloods:

Sodium $132 \mathrm{mmol} / \mathrm{l}$

(135-145)

Potassium $4.2 \mathrm{mmol} / \mathrm{l}$

(3.5-5.1)

Chloride $97 \mathrm{mmol} / \mathrm{l}$

(98-107)

Urea $5.4 \mathrm{mmol} / \mathrm{I}$

(1.7-8.3)

Creatinine $68 \mu \mathrm{mol} / \mathrm{I}$

(49-92)

Magnesium $0.73 \mathrm{mmol} / \mathrm{l}$

(0.6-1.0)

Phosphate $1.45 \mathrm{mmol} / \mathrm{l}$

(0.87-1.45)

Haemoglobin $8.9 \mathrm{~g} / \mathrm{dl}$ (11.5-15.5)

MCV 80.5 fl (80-99)

White cell count $6.01 \times 109 / 1(3-10)$

Neutrophils $2.78 \times 109 / \mathrm{I}(2-7.5)$

Lymphocytes $2.12 \times 109 /$ ( $1.5-4)$

Platelets $278 \times 109 /$ ( $150-400)$
Corrected calcium $2.39 \mathrm{mmol} / \mathrm{l}$ (2.15-2.55)

Albumin $37 \mathrm{~g} / \mathrm{l}$

(32-45)

Total protein $57 \mathrm{~g} / \mathrm{l}$

(63-83)

Glucose $4.6 \mathrm{mmol} / \mathrm{I}$

$(3.5-7.9)$

$C$ reactive protein $13.5 \mathrm{mg} / \mathrm{l}$

$(<5)$

Emily was commenced on a weight restoration programme which consisted of hydrating her with 2 litres per day of fluid orally. Gradual increase in daily calorie intake from 400 to $2000 \mathrm{kcal}$. All inpatients were kept on a salt-restrictive diet.

Emily continued on levothyroxine $100 \mu \mathrm{g}$ and was commenced on multivitamin tablets and in light of her anaemia was also commenced on ferrous sulphate $200 \mathrm{mg}$ three times daily.

Three weeks after admission, Emily began to deteriorate. Her panic attacks appeared to worsen and were associated with hyperventilation. Her BP dropped further to 67/50 mm Hg, HR 124 bpm. She had abdominal pain, headaches, nausea, feeling faint and vomited twice. She was brought by ambulance to accident and emergency.

On arrival at accident and emergency, she was found to have a BP of 94/60 mm Hg, HR $80 \mathrm{bpm}$, RR 16 bpm, Sats 100\% air and was afebrile.

On examination, she was noted to be emaciated but alert and orientated with a Glasgow Coma Scale of 15/15.

She was well perfused with a capillary refill of $<2 \mathrm{~s}$ and had normal cardiovascular, respiratory and abdominal examination. She denied any abdominal tenderness during her examination (fig 1).

Routine bloods were taken and shown:

Sodium $128 \mathrm{mmol} / \mathrm{l}$

Potassium $5.3 \mathrm{mmol} / \mathrm{I}$

Urea $4.1 \mathrm{mmol} / \mathrm{l}$

Creatinine $87 \mu \mathrm{mol} / \mathrm{l}$

Magnesium $0.8 \mathrm{mmol} / \mathrm{l}$

Phosphate $1.65 \mathrm{mmol} / \mathrm{l}$
Haemoglobin $11.8 \mathrm{~g} / \mathrm{dl}$

White cell count $7.0 \times 10^{9} / \mathrm{I}$

Neutrophils $3.0 \times 10^{9} / 1$

Lymphocytes $2.9 \times 10^{9} / \mathrm{I}$

Platelets $311 \times 10^{9} / 1$ 
She was given a provisional diagnosis of symptomatic hyponatraemia secondary to drinking large volumes of water while on a no-salt diet. She denied diuretic and laxative abuse. The possibility of adreno-cortical insufficiency was also considered.

Emily was known to suffer from anorexia nervosa, and so, it was not unexpected that she should be underweight, hypothermic, hypotensive with hyponatraemia as this would all be compatible with her diagnosis. The hyperkaelaemia could be put down to blood sampling difficulties in a peripherally shut down anorexic patient causing haemolysis and raised potassium levels. Many people with hypotension especially if they have postural hypotension can feel nauseated and dizzy on standing up.

\section{COMMENT}

Hyponatraemia is a common biochemical abnormality and can be divided into four main categories: (1) sodium loss, (2) dilutional effect (water excess), (3) inappropriate antidiuretic hormone $(\mathrm{ADH})$ secretion and (4) pseudo-hyponatraemia
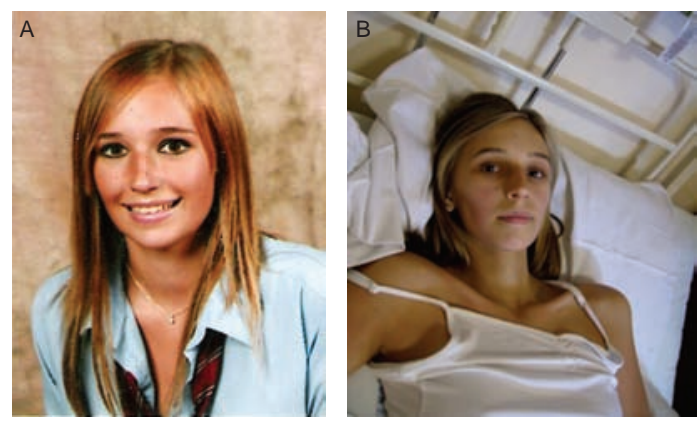

Figure 1 (A) Photo of Emily a year before the admission to hospital and (B) during hospital admission. due to displacement of sodium to the aqueous phase but still being measured as part of the total volume of plasma. This can occur in states of hyperglycaemia/hyperlipidaemia or hyperproteinaemias. The actual plasma osmolarity of sodium is actually within normal levels and, hence, does not require correcting but should be calculated using specific formulae to ensure this (table 3).

Emily was put onto a strict input/output fluid and food chart and was restricted to $500 \mathrm{ml}$ of fluid overnight and was encouraged to have salty foods, which she admitted she had been craving.

Her morning bloods showed:

\begin{tabular}{ll}
\hline Sodium $129 \mathrm{mmol} / \mathrm{l}$ & TSH $0.04 \mathrm{mlU} / \mathrm{l}$ \\
Potassium $5.4 \mathrm{mmol} / \mathrm{l}$ & T4 $21.1 \mathrm{pmol} / \mathrm{l}$ \\
Urea $6.1 \mathrm{mmol} / \mathrm{l}$ & Random glucose $4.5 \mathrm{mmol} / \mathrm{l}$ \\
Creatinine $96 \mu \mathrm{mol} / \mathrm{l}$ & Random cortisol $5 \mathrm{nmol} / \mathrm{l}$ \\
& (normal early morning range \\
& $120-660 \mathrm{nmol} / \mathrm{l}$ ) \\
\hline
\end{tabular}

Her levothyroxine was decreased to $75 \mu \mathrm{g}$, and in light of a low random cortisol level, a synacthen test was performed (table 4).

On closer inspection postsynacthen test, it was noticed that Emily had increased pigmentation of her knees, knuckles and hands (fig 2).

Emily was diagnosed with Addison's disease and was commenced on replacement doses of hydrocortisone: $10 \mathrm{mg}$ morning, $5 \mathrm{mg}$ afternoon and $5 \mathrm{mg}$ evening.

Emily's BP remained low at $84 / 48 \mathrm{~mm} \mathrm{Hg}$, HR $85 \mathrm{bpm}$. She was retching, had vomited once and had epigastric abdominal pain. She was unable to eat or drink, as she felt very unwell and her fluid input had been minimal.

Emily was commenced on intravenous hydrocortisone, given three boluses of $0.9 \%$ sodium

Table 3 Causes of hyponatraemia ${ }^{19-21}$

\begin{tabular}{|c|c|c|}
\hline Sodium loss (hypovolaemic hyponatraemia) & Normovolemic hyponatremia & Water excess (hypervolaemic hyponatraemia) \\
\hline $\begin{array}{l}\text { Skin } \\
\text { Severe sweating } \\
\text { Cystic fibrosis } \\
\text { Burns } \\
\text { Gut } \\
\text { Vomiting } \\
\text { Diarrhoea (laxative abuse) } \\
\text { Peritonitis } \\
\text { Drains/fistula } \\
\text { Haemorrhage } \\
\text { Kidney } \\
\text { Osmotic diuresis (eg, hyperglycaemia-DKA) } \\
\text { Adrenocortical insufficiency } \\
\text { Adrenocortical resistance } \\
\text { Pseudohypoaldosteronism } \\
\text { Cerebral salt-wasting syndrome } \\
\text { Tubulo-intestinal renal disease } \\
\text { Unilateral renal artery stenosis } \\
\text { Recovery phase of acute tubular necrosis } \\
\text { Diuretic abuse/iatrogenic }\end{array}$ & $\begin{array}{l}\text { Abnormal ADH release } \\
\text { Vagal neuropathy (failure of inhibition of ADH release) } \\
\text { Deficiency of ACTH or glucocorticoids (Addison's disease) } \\
\text { Hypothyroidism } \\
\text { Severe potassium depletion } \\
\text { SIADH } \\
\text { Cerebral disease (meningitis + other infections + CNS trauma) } \\
\text { Respiratory illness (pneumonia + tumours) } \\
\text { Intermittent positive-pressure ventilation } \\
\text { Drugs, eg, carbamazepine, barbiturates } \\
\text { Pain/trauma } \\
\text { Nausea/vomiting } \\
\text { ADH-like substance } \\
\text { Oxytocin } \\
\text { DDAVP } \\
\text { Unmeasured osmotically active substances stimulating osmotic } \\
\text { ADH release } \\
\text { Glucose } \\
\text { Alcohol } \\
\text { Mannitol } \\
\text { Sick cell syndrome (leakage of intracellular ions) }\end{array}$ & $\begin{array}{l}\text { Hypoalbuminaemia } \\
\text { Nephrotic syndrome } \\
\text { Liver disease/failure } \\
\text { Fluid overload } \\
\text { Congestive heart failure } \\
\text { Acute and chronic renal failure - oliguria } \\
\text { latrogenic fluid hydration } \\
\text { Psychogenic polydipsia }\end{array}$ \\
\hline
\end{tabular}

ACTH, adrenocorticotrophic hormone; ADH, antidiuretic hormone; DDAVP, 1-deamino-D-arginine vasopressin; DKA, diabetic ketoacidosis; SIADH, syndrome of inappropriate ADH secretion. 
chloride $10 \mathrm{ml} / \mathrm{kg}$ and commenced on maintenance intravenous fluid $0.9 \%$ sodium chloride.

On review, Emily's BP improved to 109/67 mm Hg, HR 110 bpm. Repeat bloods showed a gradual increase of her sodium over the accompanying days. She was commenced on oral fludrocortisone following her adrenal crisis and was put back onto oral hydrocortisone once she returned to haemodynamic stability.

Over the next few weeks, the following results came back which confirmed the diagnosis of Addison's disease.

Adrenocorticotrophin hormone (ACTH) $1918 \mathrm{ng} / \mathrm{l}$ (morning level $<100 \mathrm{ng} / \mathrm{l}$, evening $<50 \mathrm{ng} / \mathrm{l})$

Aldosterone $<75(100-800) \mathrm{pmol} / \mathrm{l}$

PRA (renin) 21 (0.5-3.1) pmol/ml/h

Adrenal antibodies: positive

\section{COMMENT}

Addison's disease is a relatively rare disorder with an estimated prevalence of $120 /$ million population; it is even rarer in the paediatric population. ${ }^{3-10}$ Addison's disease is primary adrenal failure. Autoimmune adrenitis is the most common cause of primary adrenal insufficiency postinfancy. In the UK, it accounts for $70-90 \%$ of cases. There may be positive adrenal antibodies present. Lymphocytic infiltrate cause destruction of the adrenal cortex, leading to failure of cortisol, aldosterone and adrenal androgen production. Cortisol levels are decreased with loss

Table 4 Synacthen test

\begin{tabular}{llll} 
Time (min) & 0 & 30 & 60 \\
Cortisol (nmol/l) & 5 & $<6$ & 11 \\
\hline
\end{tabular}

A normal response to the synacthen test would show a poststimulation peak of cortisol at $30 / 60 \mathrm{~min}$ of $\geq 550 \mathrm{nmol} / \mathrm{l}$ or more or an increment from base level $>200 \mathrm{nmol} / \mathrm{l}$.
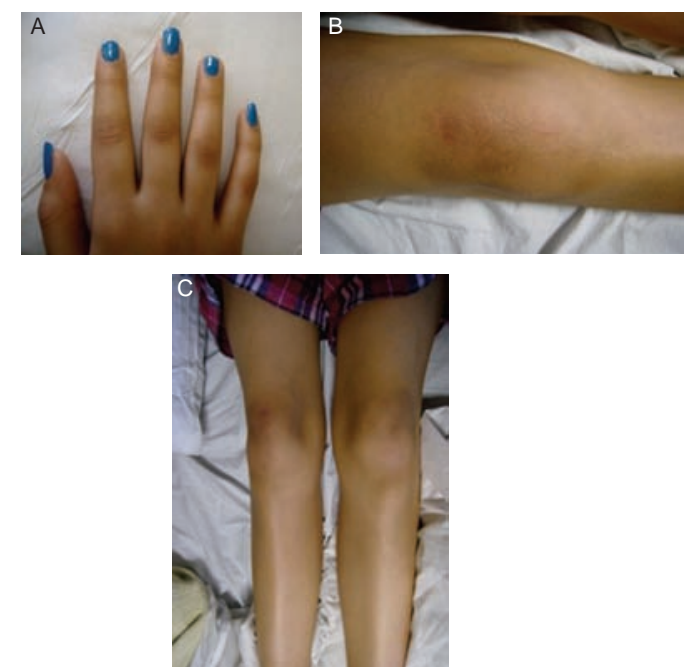

Figure $2(\mathrm{~A}-\mathrm{C})$ Hyperpigmentation of Emily's knuckles $(A)$ and knees (B and C). of circadian pattern associated with a persistent elevated ACTH level (Emily's ACTH levels were very elevated at $1918 \mathrm{ng} / \mathrm{l})$. ACTH has an affinity for melanocortin-1 receptor; thus, excess of ACTH results in hyperpigmentation. Symptoms include lethargy, weight loss, gastrointestinal complaints (anorexia, nausea, vomiting and diarrhoea), increasing skin pigmentation especially in the skin creases, old scars and buccal mucosa and salt craving. Due to the slow progression of the disease, diagnosis is often delayed, and it may only be diagnosed during an Addisonian crisis when demand for cortisol cannot be met by the failing adrenal gland. Therefore, an appropriate stress response cannot be elicited leading to vomiting, drowsiness, hypotension, hyponatraemia, hyperkalaemia, hypoglycaemia and eventually collapse and coma. Diagnosis can be confirmed by an elevated level of ACTH and lack of increase of cortisol in response to synacthen test. Renin levels are high with a low/undetectable aldosterone levels as seen with Emily. Fasting glucose is low/normal.

\section{Autoimmune polyglandular syndrome, type II}

Schmidt first described multi-endocrine organ autoimmune disease in $1926 . .^{12-14}$ His index patient had autoimmune thyroiditis and hypoadrenalism. The diagnosis is made when occurrence of autoimmune adrenal disease is found with concurrent autoimmune thyroid disease and/or type I diabetes mellitus (DM). Seventyfive per cent of autoimmune polyglandular syndrome, type II (APS2) involve thyroid and adrenal

\section{Box 1 Management of addisonian crisis ${ }^{11}$}

Fluid replacement with $20 \mathrm{ml} / \mathrm{kg} \quad 0.9 \%$ sodium chloride, initial intravenous bolus of $2 \mathrm{mg} / \mathrm{kg}$ hydrocortisone (max $100 \mathrm{mg}$ ) followed by a hydrocortisone infusion. Hypoglycaemia should also be corrected - if necessary intravenous dextrose infusion can be started to maintain normoglycaemia. Urea and electrolytes should be monitored 2 hourly, blood glucose and BP monitored hourly until normalised and stable. A strict input/output fluid balance should be kept as well as replacement of all fluid losses and correction of dehydration. Sodium should be corrected slowly and carefully to avoid osmotic demyelination syndrome (central pontine myelinolysis). Once no longer in crisis, the patient can be converted onto oral hydrocortisone (12-15 mg/m² daily in three divided doses $2: 1: 1)$ and fludrocortisone $\left(0.15-0.25 \mathrm{mg} / \mathrm{m}^{2}\right.$ daily, single dose), sodium chloride supplements should be continued until stabilisation on fludrocortisone. Hydrocortisone levels should be doubled if patient becomes unwell to keep up with the body's requirement under stress. The patient should wear a medical alert bracelet in case of emergency and carry an adrenal insufficiency card in their wallet. 
failure with no preference for which organ fails first. Approximately $10 \%$ of APS2 have a combination of all three (adrenal, thyroid and type I DM). Patients with APS2 are at increased risk of developing other autoimmune diseases (table 5). At onset, if APS2 is suspected, it is worth testing patients in case they are at risk of complete APS2 for adrenal cortex antibodies and 21-hydroxylase autoantibodies and consider performing a synacthen test if they have presented with type I DM. If they presented with Addison's disease, it is worth testing for islet-cell antibodies, autoantibodies to glutamic acid decarboxylase, second islet autoantigen and carrying out an oral glucose tolerance test which may reveal a subclinical impairment before the onset of type I DM. All patients with APS2 should be tested for thyroid autoantibodies if not yet checked. Regular screening for coeliac disease should be performed, but no regular screening is required for other related autoimmune diseases, although they should be borne in mind if symptoms of any start to develop. ${ }^{14}$

Only $1 \%$ of patients with autoimmune thyroid disease alone or type I DM develop adrenal insufficiency; therefore, screening for adrenal insufficiency is not indicated unless there is a strong family history or clinical suspicion. However, thyroid function and coeliac disease should be routinely checked for in patients with type I DM.

Prevalence of APS2 is thought to be between 1.5 and 4.5/100,000 population. It occurs most commonly in middle-aged women with an average age of onset of 35-40 years and female/male ratio of 4:1.

APS2 is thought to result from cell-mediated immune responses that attack the end endocrine organ. The genetic basis for APS2 is not yet known but appears to be linked to alleles within the HLA-DR3-carrying haplotype and a polymorphism of the cytotoxic $\mathrm{T}$ lymphocyte antigen-4 (CTLA4). ${ }^{15}$ APS2 may be the result of

Table 5 Autoimmune disorders associated with autoimmune polyglandular syndrome type ${ }^{113} 15$

Endocrine disorders
Type I diabetes mellitus
Autoimmune thyroid disease (Hashimoto's thyroiditis, idiopathic myxoedema + Graves'
disease)
Addison's disease
Hypogonadotrophic hypogonadism
Non-endocrine
Vitiligo
Alopecia
Atrophic gastritis
Pernicious anaemia
Coeliac disease
Myasthenia gravis
Chronic autoimmune hepatitis
Rheumatoid arthritis
Idiopathic thrombocytopenia purpura
Sjögren's syndrome
Lymphocytic hypophysitis

\section{Clinical messages}

Hypothyroidism is a common condition. Occasionally, it may be associated with other autoimmune conditions.

- If patients deteriorate rather than improve following initiation of thyroid replacement therapy, this should trigger further investigations for other conditions including primary adrenal insufficiency.

- In patients with both hypothyroidism and primary adrenal insufficiency, restoration of euthyroid state without correction of the adrenal insufficiency first can cause an increase in metabolic rate and push them into an addisonian crisis.

an autoimmune response to an external antigen in genetically susceptible people. Approximately $50 \%$ of patients with APS2 report a family history of polyglandular failure.

\section{A note of caution and lessons to be learnt}

Although hypothyroidism is a common occurrence, it can occur in combination with autoimmune failure of other endocrine glands such as seen in autoimmune polyglandular syndrome type II. ${ }^{13} 1617$ If this is the case, by restoring a patient to a euthyroid state, it may precipitate adrenal failure and Addisonian crisis as it did in Emily's case. Hypothyroidism reduces cortisol clearance thus increasing the basal cortisol level; however, once hypothyroidism is corrected, cortisol clearance increases thus reducing circulating cortisol availability. Hypothyroidism reduces the body's metabolic rate, which reduces the body's cortisol requirements. By becoming euthyroid, the metabolic rate of the individual returns to normal, but the cortisol requirement cannot be matched by the failing adrenal gland; therefore, the patient goes into Addisonian crisis. Physicians should, therefore, be particularly suspicious of patients who deteriorate postcommencement of hypothyroid treatment or have one or more autoimmune endocrine diseases and develop non-specific/ serious illness. A morning cortisol level with paired ACTH level should be checked to ensure it falls within normal range. Paired testing is done by taking both blood levels at the same time so they can be interpreted in relation to each other, such that if a morning cortisol is sufficiently high, then the ACTH should be suppressed in relation to this. If there is any doubt, then a synacthen test should be performed as the gold standard for diagnosing primary adrenal insufficiency.

\section{Competing interests None.}

Patient consent Obtained.

Provenance and peer review Commissioned; externally peer reviewed.

Contributors The author would like Dr Vaseem Hakeem who supervised and edited the article to be acknowledged. 


\section{REFERENCES}

1. Carskadon MA. Patterns of sleep and sleepiness in adolescents. Pediatrician 1990;17:5-12.

2. Raine J, Donaldson M, Gregory J. Thyroid disorders. In: Raine J, Donaldson M, Gregory J, et al, eds. Practical endocrinology and diabetes in children. Chapter 6. Malden: Blackwell, 2001:85-99.

3. Wales J, Wit JM, Rogol A. Goiter. In: Wales J, Wit JM, eds Paediatric endocrinology and growth. 2nd edn. Chapter 9.

Maryland Heights: Saunders, 2003:181-91.

4. Gowers SG. Management of eating disorders in children and adolescents. Arch Dis Child 2008;93:331-4.

5. Katona C, Robertson M. Eating disorders. In: Katona C, Robertson M, eds. Psychiatry at a glance. 2nd edn. Chapter 11. Oxford: Blackwell Science, 2001:28-9.

6. Levey R, Corbet W, Curfman MD. Anorexia Nervosa. emedicine, 2006. http://emedicine.medscape.com/ article/286063-overview (accessed Apr 2010).

7. Muñoz MT, Argente J. Anorexia nervosa in female adolescents: endocrine and bone mineral density disturbances. Eur J Endocrinol 2002;147:275-86.

8. Raine J, Donaldson M, Gregory J. Adrenal disorders. In: Raine J, Donaldson M, Gregory J, et al, eds. Practical endocrinology and diabetes in children. Chapter 8. Malden: Blackwell, 2001:117-35.

9. Turner J. Addison's disease. Vol 29. Sydney: The Medicine Publishing Company, 2001:11,19-21.

10. Ten S, New M, Maclaren N. Clinical review 130: Addison's disease 2001. J Clin Endocrinol Metab 2001;86:2909-22.

11. Hindmarsh P. Adrenal Insufficiency (Emergency Management). Clinical guidelines. UCL Institute of Child Health, 2008. http://www.ich.ucl.ac.uk/clinical_information/clinical guidelines/cmg guideline 00072 (accessed Oct 2008).
12. Schmidt MB. Eine biglanduloma Erkankung (Nebennieren und Schilddruse) bei Morbus Addisonii. Verth Dtsch Ges Pathol 1926;21:212-21

13. Graves $\mathbf{L}$ 3rd, Klein RM, Walling AD. Addisonian crisis precipitated by thyroxine therapy: a complication of type 2 autoimmune polyglandular syndrome. South Med J 2003;96:824-7.

14. Betterle C, Dal Pra C, Mantero F, et al. Autoimmune adrenal insufficiency and autoimmune polyendocrine syndromes: autoantibodies, autoantigens, and their applicability in diagnosis and disease prediction. Endocr Rev 2002:23:327-64.

15. Betterle C, Lazzarotto F, Presotto F. Autoimmune polyglandular syndrome Type 2: the tip of an iceberg? Clin Exp Immunol 2004;137:225-33.

16. Shulman DI, Palmert MR, Kemp SF; Lawson Wilkins Drug and Therapeutics Committee. Adrenal insufficiency: still a cause of morbidity and death in childhood. Pediatrics 2007;119:e484-94.

17. Murray JS, Jayarajasingh R, Perros P. Lesson of the week: Deterioration of symptoms after start of thyroid hormone replacement. BMJ 2001;323:332-3

18. WHO. The ICD-10 Classification of Mental and Behavioural Disorders. Geneva: WHO, 1992.

19. Kumar P, Clark ML. Water, electrolytes and acid-base homeostasis. In: Kumar P, Clark ML, eds. Clinical medicine. 4th edn. Chapter 10. Philadelphia: WB Saunders, 1998:597-624.

20. Beattie M, Champion M. Acid-base, fluid and electrolytes In: Beattie M, Champion M, eds. Essential revision notes in paediatrics for the MRCPCH. 1st edn. Chapter 6. Cheshire: PasTest, 2002:217-29.

21. Vellaichamy M. Hyponatraemia. emedicine, 2009. http:// emedicine.medscape.com/article/907841-overview laccessed Apr 2009) 